\title{
A importância do ensino de Libras desde a educação infantil: uma questão de
}

\section{inclusão social}

\author{
The importance of teaching Libras from early childhood education: a matter of social inclusion \\ La importancia de enseñar Libra desde la educación infantil: una cuestión de inclusión social
}

Recebido: 26/09/2021 | Revisado: 30/09/2021 | Aceito: 30/09/2021 | Publicado: 01/10/2021

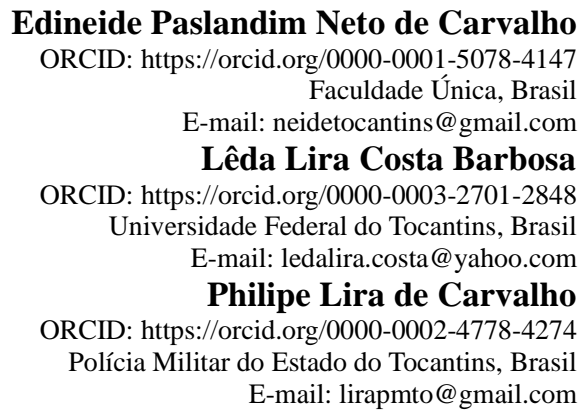

\begin{abstract}
Resumo
Este artigo teve como intuito descrever a importância do ensino de Língua Brasileira de Sinais - Libras desde a educação infantil. Para isso foi feita uma análise histórica da evolução do ensino de Libras na educação brasileira, bem como das Legislações que têm como foco garantir a educação inclusiva dos alunos com surdez no país. Além de verificar as políticas públicas educacionais direcionadas à educação especial. Nesse sentido, o ensino de Libras, apesar de garantido por leis nacionais, mostra uma série de dificuldades nas escolas, principalmente nas séries dos anos iniciais, devido à falta de intérpretes de língua de sinais dentro da sala de aula. Na parte metodológica deste trabalho científico foi utilizada a pesquisa bibliográfica, documental, de natureza aplicada, utilizando-se do método dedutivo e da abordagem qualitativa. Dessa forma, a pesquisa concluiu que o ensino de Libras, embora esteja normatizado nas escolas, necessita de políticas públicas efetivas voltadas a educação especial, de modo a garantir a proteção da minoria muitas vezes excluída.
\end{abstract}

Palavras-chave: Libras; Inclusão; Educação infantil; Efetividade.

\begin{abstract}
This article aimed to describe the importance of teaching Brazilian Sign Language - Libras since early childhood education. For this, a historical analysis of the evolution of the teaching of Libras in Brazilian education was carried out, as well as of the Legislation that focuses on guaranteeing the inclusive education of students with deafness in the country. In addition to verifying public educational policies aimed at special education. In this sense, the teaching of Libras, despite being guaranteed by national laws, shows a series of difficulties in schools, especially in the early grades, due to the lack of sign language interpreters in the classroom. In the methodological part of this scientific work, bibliographical and documental research of an applied nature was used, using the deductive method and the qualitative approach. Thus, the research concluded that the teaching of Libras, although it is standardized in schools, needs effective public policies aimed at special education, in order to guarantee the protection of the often excluded minority.
\end{abstract}

Keywords: Pounds; Inclusion; Child education; Effectiveness.

\section{Resumen}

Este artículo tuvo como objetivo describir la importancia de la enseñanza de la Lengua de Signos Brasileña - Libra desde la educación infantil. Para ello, se realizó un análisis histórico de la evolución de la enseñanza de Libras en la educación brasileña, así como de la Legislación que se enfoca en garantizar la educación inclusiva de los estudiantes con sordera en el país. Además de verificar las políticas educativas públicas orientadas a la educación especial. En este sentido, la enseñanza de Libras, a pesar de estar garantizada por las leyes nacionales, muestra una serie de dificultades en las escuelas, especialmente en los primeros grados, debido a la falta de intérpretes de lengua de signos en el aula. En la parte metodológica de este trabajo científico se utilizó la investigación bibliográfica y documental de carácter aplicado, utilizando el método deductivo y el enfoque cualitativo. Así, la investigación concluyó que la enseñanza de Libra, aunque está estandarizada en las escuelas, necesita políticas públicas efectivas dirigidas a la educación especial, a fin de garantizar la protección de la minoría muchas veces excluida.

Palabras clave: Libras; Inclusión; Educación infantil; Eficacia. 


\section{Introdução}

O intuito de garantir um ensino eficiente para indivíduos surdos é um assunto muito complexo e amplamente discutido no Brasil, que engloba problemas ainda não resolvidos nas escolas. Diante isso, este artigo em seu objetivo geral pretende analisar a relevância do ensino de Libras desde a educação infantil, a qual compreende a primeira etapa da educação básica, englobando crianças da faixa etária até 5 (cinco) anos. Diante disso, o autor Sacks (2010) menciona que o ensino de língua de sinais deve ser introduzido o mais cedo possível, para evitar que o desenvolvimento do aluno seja prejudicado.

Para fazer o levantamento dessa importância, foi estabelecido como objetivos específicos: 1) realizar um levantamento bibliográfico de produções envolvendo a evolução do ensino Libras no Brasil; 2) verificar as legislações existentes brasileiras que garantem o ensino de Libras; 3) identificar as políticas públicas de educação inclusiva.

Este trabalho tem sua importância para o meio acadêmico, pois permitirá uma análise de vários materiais bibliográficos atinentes ao ensino de Libras, a qual enquanto área de conhecimento se trata debatido no meio âmbito acadêmico, principalmente em Congressos Científicos.

Esta pesquisa também é imprescindível do ponto de vista social, visto que envolve questões de inclusão social de uma minoria no ambiente escolar para que possam ter o direito de aprender em condições iguais. Em relação às questões jurídicas, este artigo corrobora as legislações sobre garantias de educação especial: Constituição Federal do Brasil (Brasil, 1988); Lei $\mathrm{n}$. 7.853 (Brasil, 1989); Lei n. 8.069 (Brasil, 1990); Lei n. 9.394 (Brasil, 1996); Lei n. 10.172 (Brasil, 2001); Lei n. 10.436 (Brasil, 2002); e Decreto 5.626 (Brasil, 2005).

No tocante à relevância científica, a Libras proporciona o desenvolvimento intelectual, social e linguístico da pessoa que a utiliza enquanto instrumento comunicativo, possibilitando seu acesso a um vasto conhecimento cultural científico, além de interagir no grupo social, ao qual pertence.

Dessa maneira, o problema estudado partiu-se da necessidade da percepção de dificuldades que muitos discentes com surdez encontram no ambiente escolar, o que acaba comprometendo seu aprendizado, devido à falta de um intérprete de língua de sinais desde as séries iniciais. Partindo-se da premissa que a escola necessita reformular seu currículo para atender a individualidade de cada aluno.

Assim, o presente artigo para ser melhor compreendido, após essa introdução, fez um apanhado histórico sobre a evolução do ensino da Línguas de Sinais Brasileira no país. Por conseguinte, foram analisadas as legislações brasileiras atinentes ao ensino de Libras e foi realizada uma análise de políticas públicas de educação inclusiva.

\section{Metodologia}

A metodologia do trabalho, conforme Mazucato (2018) enquadra-se como bibliográfica e documental, uma vez que foram usados livros e artigos científicos a respeito da temática, bem como foram levantadas normas atinentes ao trabalho.

Além do mais, a pesquisa foi de natureza aplicada, a qual segundo Fernandes Júnior e Santos (2021, p. 28) objetiva gerar conhecimentos para aplicação prática dirigidos à solução de problemas específicos, assim após o levantamento da problemática podem ser aplicados novas informações sobre seu teor com vistas a aplicação de uma solução prática nas escolas, uma vez que foram levantadas situações verídicas.

No tocante aos objetivos, a pesquisa enquadra-se como descritiva, pois foram descritas características de determinada população, através de uma série de informações pesquisadas (Gil, 2017).

Ademais, o estudo utilizou-se o método dedutivo, uma vez que transforma enunciados gerias em particulares, ou seja, o ponto de partida anterior é uma premissa universal e chega em uma premissa particular (Aragão \& Neta, 2017). 
A pesquisa fez uma abordagem qualitativa, uma vez foram interpretadas as legislações correspondentes ao objeto da pesquisa e segundo Rodrigues e Gonçalves (2020, p. 127) "tem o objetivo de qualificar os resultados, ampliando a compreensão dos resultados e possibilitando a intervenção da sociedade em diversos campos de atuação".

\section{Resultados e Discursões}

\subsection{Breve histórico sobre o ensino de Libras no Brasil}

A educação de pessoas surdas iniciou no Brasil no Império de D. Pedro II, quando este convidou o professor francês Hernest Huet, surdo aos 12 anos de idade, para fundar a primeira escola exclusiva para pessoas do sexo masculino no país (Sabanai, 2007).

Ainda segundo Sabanai (2007), a escola foi denominada Imperial Instituto de Surdos-Mudos, criada pela Lei no 839 , de 26 de setembro de 1857, dirigida por seu fundador de 1857 a 1861, tendo esse nome alterado para Instituto Nacional de Educação de Surdos - INES2, com o advento da República do Brasil.

No entanto, conforme Pereira (2013, p. 76):

[...] em 6 de novembro de 1880 aconteceu na cidade de Milão, na Itália, o Segundo Congresso Internacional de Educação de Pessoas Surdas. Nesse evento os congressistas, professores de Surdos, decidiram que todos os alunos com deficiência auditiva deveriam ser ensinados pelo Método Oral Puro2. Com isso, a língua de sinais deixou de ter o status de língua e os Surdos enfrentaram um período de cem anos sem poder utilizar a forma de comunicação natural no ambiente escolar.

Diante disso, ao longo da história, os educadores perceberam que as pessoas surdas, por não estarem acostumados com a língua falada, não tinham êxito em dar significação às palavras reproduzidas oralmente que aprendiam na escola (Pereira, 2013).

Assim, mesmo com o avançar dos anos, apenas o supracitado Instituto oficial permaneceu responsável por receber os discentes surdos do Brasil, além dos países da América Latina. E só em 1951, que o Ministério da Educação (MEC) organizou para que fossem criados e instalados cursos de especialização nessa área para formação de professores (Sabanai, 2007).

A partir da década de 50, com a instalação dos cursos voltados à especialização, os surdos do Brasil puderam criar a Língua Brasileira de Sinais - Libras, a qual foi originada pela combinação da língua de sinais da França com outros sistemas de comunicação que já eram usados pelos surdos de diversos locais (Brasil, 1997). E que segundo Nader et al. (2007), essa deficiência foi suprida com o incremento da Libras, a qual se identifica como língua própria e gesto-visual. Com essa evolução, o Instituto Nacional de Educação de Surdos tornou-se um Centro Nacional de Referência na área da surdez, tendo as instruções em Libras e ainda o Português como segunda língua.

\subsection{Aspectos legais e políticas públicas sobre ensino de Libras}

Ao longo dos anos, o ensino de Libras ganhou mais espaço no país, surgindo uma série de Legislações a respeito para garantir os direitos do ensino e as políticas educacionais a pessoas com necessidades educacionais especiais, conforme Quadro 1 a seguir: 
Quadro 1 - Compêndio de algumas Legislações a respeito de Libras

\begin{tabular}{|c|c|}
\hline Constituição Federal do Brasil & $\begin{array}{l}\text { Art. 208: } \\
\text { O dever do Estado com a educação será efetivado mediante a garantia de: } \\
\text { III - atendimento educacional especializado aos portadores de deficiência, preferencialmente } \\
\text { na rede regular de ensino; } \\
\text { V - acesso aos níveis mais elevados do ensino, da pesquisa e da criação artística, segundo a } \\
\text { capacidade de cada um; } \\
\S 1^{\circ} \text { - O acesso ao ensino obrigatório e gratuito é direito público e subjetivo. } \\
\text { Art. } 227 \text { : } \\
\S 1^{\circ}-\text { O Estado promoverá programas de assistência integral à saúde da criança e do } \\
\text { adolescente, admitida a participação de entidades não-governamentais e obedecendo os } \\
\text { seguintes preceitos: } \\
\text { II - Criação de programas de prevenção e atendimento especializado para os portadores de } \\
\text { deficiência física, sensorial ou mental, bem como de integração social do adolescente portador } \\
\text { de deficiência, mediante o treinamento para o trabalho e a convivência, e a facilitação do } \\
\text { acesso aos bens e serviços coletivos, com a eliminação de preconceitos e obstáculos } \\
\text { arquitetônicos (Brasil, 1988). }\end{array}$ \\
\hline $\begin{array}{l}\text { Lei } n^{\circ} 7.853 / 89 \text { - Dispõe sobre o apoio às } \\
\text { pessoas portadoras de deficiência, sua } \\
\text { integração social, sobre a Coordenadoria } \\
\text { Nacional para Integração da Pessoa } \\
\text { Portadora de Deficiência }\end{array}$ & $\begin{array}{l}\text { Art. } 1^{\circ} \text { Ficam estabelecidas normas gerais que asseguram o pleno exercício dos direitos } \\
\text { individuais e sociais das pessoas portadoras de deficiências, e sua efetiva integração social, } \\
\text { nos termos desta Lei (Brasil, 1989). }\end{array}$ \\
\hline $\begin{array}{l}\text { Lei } n^{\circ} 9.394 / 96 \text { - Estabelece as diretrizes } \\
\text { e bases da educação nacional. }\end{array}$ & $\begin{array}{l}\text { Art. } 4^{\circ} \text { O dever do Estado com educação escolar pública será efetivado mediante a garantia de: } \\
\text { [...] } \\
\text { III - atendimento educacional especializado gratuito aos educandos com deficiência, } \\
\text { transtornos globais do desenvolvimento e altas habilidades ou superdotação, transversal a } \\
\text { todos os níveis, etapas e modalidades, preferencialmente na rede regular de ensino; (Brasil, } \\
\text { 1996). }\end{array}$ \\
\hline $\begin{array}{l}\text { Lei } \mathrm{n}^{\circ} 10.172 / 01 \text { - Aprova o Plano } \\
\text { Nacional de Educação e dá outras } \\
\text { providências. }\end{array}$ & $\begin{array}{l}\text { O Plano Nacional de Educação estabelece um total de } 27 \text { objetivos e metas para a educação } \\
\text { das pessoas com necessidades educacionais especiais (Brasil, 2001). }\end{array}$ \\
\hline $\begin{array}{l}\text { LEI N. }{ }^{\circ} 10.436 / 2002 \text { - Dispõe sobre a } \\
\text { Língua Brasileira de Sinais - Libras e dá } \\
\text { outras providências. }\end{array}$ & $\begin{array}{l}\text { Art. } 1^{\circ} \text { É reconhecida como meio legal de comunicação e expressão a Língua Brasileira de } \\
\text { Sinais - Libras e outros recursos de expressão a ela associados (Brasil, 2002). }\end{array}$ \\
\hline $\begin{array}{l}\text { Decreto } 5.626 \text { de } 22 \text { de dezembro de } \\
2005 \text { (regulamenta a Lei 10.436/02). }\end{array}$ & $\begin{array}{l}\text { Art. } 3^{\circ} \text { A Libras deve ser inserida como disciplina curricular obrigatória nos cursos de } \\
\text { formação de professores para o exercício do magistério, em nível médio e superior, e nos } \\
\text { cursos de Fonoaudiologia, de instituições de ensino, públicas e privadas, do sistema federal de } \\
\text { ensino e dos sistemas de ensino dos Estados, do Distrito Federal e dos Municípios (Brasil, } \\
\text { 2005). }\end{array}$ \\
\hline
\end{tabular}

Fonte: Organizado pelos autores com base nas Referências citadas no Quadro (2021).

Diante dessas informações, verificou-se o tanto que o Brasil evoluiu ao estampar em regramentos jurídicos nacionais o direito ao ensino as pessoas com algum tipo de deficiência, incluindo as surdas. O grande problema, segundo Nader et al. (2007, p.4), é que:

a Língua é reconhecida, o oralismo não é mais bem visto em detrimento do bilinguismo. Porém, ao colocarmos um aluno surdo em uma sala de aula em que ninguém sabe LIBRAS, em que não há intérprete, em que não há algumas vezes nem um professor especializado, a este aluno está sendo imposta a oralização e ao não uso da Língua de Sinais. $\mathrm{Na}$ realidade das Escolas Estaduais de Campinas a maioria dos alunos surdos não tem contato na escola com outros surdos ou ouvintes fluentes em Libras e, por este motivo, não usam a Língua de Sinais, perdendo assim, inclusive, a sua identidade surda.

Conforme explicação acima, embora o Brasil tenha garantido por leis esta acessibilidade e o direito ao ensino aos alunos surdos, infelizmente essa inclusão não é efetiva, visto que os demais alunos não sabem se comunicar por Libras, e por muitas vezes não tem intérpretes para auxiliá-los. Nesse prisma, Sacks (2010), explica que a língua de sinais deve ser iniciada o mais breve possível, para que não comprometa o aprendizado do discente de forma retardatária. 
Por isso, a necessidade do ensino de Libras desde a educação infantil, com o intuito de aprendizado e a efetiva inclusão do discente com surdez. Sendo estas uma das exigências constantes no Decreto $\mathrm{n}^{\circ}$ 5.626, de 22 de dezembro de 2005, que regulamentou o Ensino de Libras, em seu Art. 14, "II - ofertar, obrigatoriamente, desde a educação infantil, o ensino da Libras e também da Língua Portuguesa, como segunda língua para alunos surdo"s (Brasil, 2005).

Ademais, "para o ensino bilíngue, caso o professor precise, pode-se fazer uso de um intérprete dentro de sala de aula fazendo traduções simultâneas para o grupo de alunos. É uma proposta educacional que oferece acesso ao aluno surdo nas duas línguas, o que surgiu por reinvindicações dos próprios surdos” (Ferreira, 2016, p. 21).

Conforme a Lei de Diretrizes e Bases da Educação Nacional em seu:

Art. 29. A educação infantil, primeira etapa da educação básica, tem como finalidade o desenvolvimento integral da criança de até 5 (cinco) anos, em seus aspectos físico, psicológico, intelectual e social, complementando a ação da família e da comunidade (Brasil, 1996).

Portanto, é no início das atividades escolares que deve ser inserida a linguagem de Sinais. De igual modo descreve

Basso, Strobel e Masutti (2009, p. 4):

É importante lembrar que o ensino da LS [língua de sinais] é uma proposta com fins definidos: o aluno surdo que adquire e aprende a LS no início de sua escolarização - educação infantil e primeira etapa do ensino fundamental - é aquele que terá experiências e competência linguística suficiente para, não somente acessar o conhecimento, mas também transformar esse conhecimento de forma crítica e ativa. E mais do que isso: a língua de sinais é a língua por meio da qual as identidades surdas são constituídas e a cultura surda se manifesta.

Ao contrário disso, o que acontece hoje na prática em relação as instituições federais de ensino são as seguintes exigências:

Art. 22. As instituições federais de ensino responsáveis pela educação básica devem garantir a inclusão de alunos surdos ou com deficiência auditiva, por meio da organização de:

$[\ldots]$

II - escolas bilíngues ou escolas comuns da rede regular de ensino, abertas a alunos surdos e ouvintes, para os anos finais do ensino fundamental, ensino médio ou educação profissional, com docentes das diferentes áreas do conhecimento, cientes da singularidade linguística dos alunos surdos, bem como com a presença de tradutores e intérpretes de Libras - Língua Portuguesa.

[...]

Art. 23. As instituições federais de ensino, de educação básica e superior, devem proporcionar aos alunos surdos os serviços de tradutor e intérprete de Libras - Língua Portuguesa em sala de aula e em outros espaços educacionais, bem como equipamentos e tecnologias que viabilizem o acesso à comunicação, à informação e à educação.

$[\ldots]$

$\S 2^{\circ}$ As instituições privadas e as públicas dos sistemas de ensino federal, estadual, municipal e do Distrito Federal buscarão implementar as medidas referidas neste artigo como meio de assegurar aos alunos surdos ou com deficiência auditiva o acesso à comunicação, à informação e à educação (Brasil, 2005).

Diante disso, verificou-se que algumas das Políticas Públicas que tratam da necessidade de se ter em sala de aula um profissional intérprete de Libras, na ocasião de se ter algum discente surdo. No intuito de garantir a ele o direito a se comunicar, por meio da linguagem de sinais. Na escola, até a $4^{\mathrm{a}}$ série do Ensino Fundamental, exige-se ao menos um professor formado em Pedagogia com domínio de Libras. Ao passo que a partir da $5^{\text {a }}$ série, caso haja algum aluno surdo, é obrigatório um intérprete de Libras em sala de aula, para promover a acessibilidade do conteúdo estudo a este discente.

Ademais, com base nas Leis, não é o discente surdo, conforme Nader et al. (2007, p. 6), "que tem que se adaptar para ter acesso ao conhecimento e a maneira de ensino voltada para os alunos não deficientes, mas a escola que precisa se adaptar e 
adaptar seus materiais e métodos para que o aluno deficiente tenha acesso ao conhecimento". Portanto, é latente o tanto que as escolas estão aquém de garantir esse direito.

Pois bem, é sabido que embora a lei tenha a função de regulamentar a Educação Especial, indicando a inclusão como proposta de trabalho, isso não tem se efetivado na prática aos surdos, visto que carece de intérpretes no ambiente escolar.

Ainda segundo as concepções de Nader et al. (2007, p. 10):

As Políticas Públicas teoricamente postulam que para a educação inclusiva acontecer de forma eficiente são necessárias a formação e a capacitação de professores. Porém, encontramos o problema de não estar explícito nas leis de que forma esta capacitação deve acontecer, e o que vemos na prática é que os cursos são superficiais e não dão conta de preparar os professores para receber um aluno surdo que, se tratando de alunos especiais, é aquele que tem uma língua diferente do Português. O segundo problema é que, apesar de constar nas Políticas Públicas que os cursos de capacitação devem acontecer, a maior parte das escolas que recebem surdos ainda não se envolveram nestas iniciativas. Com as visitas realizadas até o momento, vimos que nada do que dito nas leis estão realmente vigentes. Em nenhumas das escolas visitadas possuem intérpretes de Libras para os alunos surdos, ao contrário, além de não ter, as professoras das salas de recursos e professoras itinerantes fazem o papel de intérprete durantes os atendimentos traduzindo o conteúdo visto pelos alunos em sala de aula, ajudando-os a fazerem provas e trabalhos etc.

A citação supracitada destaca a necessidade de os docentes serem capacitados para a eficiência da educação inclusiva, sendo que o grande problema já é iniciado pela falta legislações que regulamentem como essa capacitação deve acontecer. Visto que à falta de profissionais habilitados como intérpretes, professores itinerantes acabam fazendo esse papel de auxiliar o discente surdo.

Nos ensinamentos de Quadros (2008), o fato da língua de sinais ser natural, em decorrência de ser adquirida de maneira espontânea pela pessoa surda em contato com outras pessoas que usam da mesma língua e considerando a situação que a língua oral é alcançada de maneira sistematizada, devido a isso, as pessoas com surdez têm o direito de serem ensinadas na língua de sinais com uma proposta bilíngue. Dessa maneira, a educação para as pessoas com surdez precisa estar voltada à perspectiva de que a língua de sinais é a base que eles necessitam para seu acesso ao processo educativo.

Caridade (2020, p. 8) demonstra em sua pesquisa a uma aluna com surdez no ensino fundamental em uma escola do Macapá que "de acordo com o caso foi observado a necessidade de continuar os trabalhos da Língua de Sinais Brasileira LIBRAS (L1) e Língua Portuguesa (L2), pois, a educanda apresentou necessidades e interesses em desenvolver seu conhecimento para realizar atividades nas duas línguas e precisa de complementação do ensino nos referidos idiomas".

Assim, para garantir a efetiva educação inclusiva, Mantoan (2021) enfatiza que é preciso discutir e ultrapassar os pontos controvertidos que existem entre a Lei de Diretrizes e Bases da Educação Nacional (Lei 9394/96) e a Carta Magna do Brasil de 1988. A referida autora ainda menciona que é necessário fazer uma reflexão acerca dos caminhos propostos pelas políticas de educação, as quais continuam apenas apagando incêndio, e com isso, não avançam e nem acompanham as inovações, proporcionando as questões que levam à exclusão escolar.

Neste raciocínio, conforme Alexandrino e Deus (2014), a escola sofre pressões, no intuito que se adeque dentro das limitações das pessoas excluídas, inserindo-as no contexto social, buscando igualdade e direito de participação na cidadania, sem que haja desigualdades e dificuldades. Ainda segundo o autor:

Neste âmbito, há muitos esforços dentro de órgãos responsáveis pela transformação da sociedade a fim de possibilitar a construção da tão almejada educação inclusiva com todos os requisitos necessários para que torne-se eficaz. A preocupação da política inclusiva está centrada com a desinstitucionalização da exclusão, quer seja na escola ou em qualquer estrutura social. As políticas inclusivas devem expor seus efeitos nas relações materiais através das instituições onde são evidenciadas as práticas discriminatórias (Alexandrino \& Deus, 2014, p. 7-8).

Portanto, a inclusão na educação é uma tarefa complexa, enquanto paradigma educacional, necessita-se ter como objetivo capacitação dos profissionais, recursos didáticos e estratégias para formação de um ambiente escolar acolhedor, onde 
não existam exigências ou critérios de seleção ou discriminação de acesso. E a efetivação do ensino de Libras ocorra desde a Educação Infantil, para inserir o discente com surdez no contexto educacional desde os primeiros anos da escola.

\section{Considerações Finais}

A pesquisa buscou fazer uma análise da importância do ensino de Libras desde a educação infantil, na qual foram levantados os aspectos históricos, dispositivos legais e políticas públicas de inclusão escolar.

Ao longo do trabalho, ficou constatado que o objetivo geral e os objetivos específicos foram alcançados, uma vez que foram bem discorridos no presente artigo científico. E para a resolução da problemática do trabalho, conclui-se que há necessidade de implementação de políticas públicas mais efetivas voltadas a educação inclusiva.

No decorrer do trabalho, foram levantados pontos imprescindíveis à educação de indivíduos surdos e a relevância que a Libras representa na vida desses indivíduos desde as séries iniciais, possibilitando um ambiente escolar bilíngue.

Embora, seja necessária uma propagação de informações e de conhecimento referente aos mecanismos para adquirem o conhecimento da linguagem de sinais, incluindo aspectos do ambiente adequado, capacitação dos profissionais, recursos didáticos e estratégias voltadas ao ensino usual desse processo ensino-aprendizagem. Isso possibilitará professores preparados a receberem alunos com surdez no ambiente escolar, incluindo-os de fato nesse processo.

Portanto, deseja-se que esse trabalho no meio acadêmico não possa exauri o tema, mas que possa colaborar com o conhecimento adquirido para trabalhos futuros. Pelo fato que muito ainda precisa ser feito para os indivíduos surdos no contexto educacional para resguardar um aprendizado aceitável e respeitas suas individualidades. As instituições escolares necessitam garantir toda logística para que esses discentes possam ser vistos sob uma perspectiva de potencialidades e não de limitações.

\section{Referências}

Alexandrino, B. B., \& Deus, P. A. S. de. (2014) A efetividade do direito na inclusão escolar dos portadores do transtorno do espectro do autismo. http://publicadireito.com.br/artigos/?cod=f29c0f1c5f3cc955.

Aragão, J. W. M. De., \& Neta, M. A. H. M. (2017). Metodologia científica. Universidade Federal da Bahia. Salvador. Faculdade de Educação, Superintendência de Educação a Distância. Produção de Mídias para educação online.

Basso, I. M. de S., Strobel, K. L., \& Masutti, M. (2009). Metodologia de ensino de Libras - L1. Florianópolis: Centro de Comunicação e Expressão, UFSC. https://www.libras.ufsc.br/colecaoLetrasLibras/eixoFormacaoPedagogico/metodologiaDeEnsinoEmLibrasComoL1/assets/631/TEXTO-

BASE_SEM_AS_IMAGENS_.pdf.

Brasil. (1988). Constituição da República Federativa do Brasil de 1988. Planalto Brasília. http://www.planalto.gov.br/ccivil_03/constituicao/constituicao.htm.

Brasil. (1989). Lei $\mathrm{n}^{\circ}$ 7.853, de 24 de outubro de 1989. Dispõe sobre o apoio às pessoas portadoras de deficiência, sua integração social, sobre a Coordenadoria Nacional para Integração da Pessoa Portadora de Deficiência - Corde, institui a tutela jurisdicional de interesses coletivos ou difusos dessas pessoas, disciplina a atuação do Ministério Público, define crimes, e dá outras providências. http://www.planalto.gov.br/ccivil_03/leis/17853.htm.

Brasil. (1990). Lei $\mathrm{n}^{\mathrm{o}}$ 8.069, de 13 de julho de 1990. Dispõe sobre o Estatuto da Criança e do Adolescente e dá outras providências. http://www.planalto.gov.br/ccivil_03/leis/18069.htm

Brasil. (1996). Lei $\mathrm{n}^{\mathrm{o}}$ 9394, 20 de dezembro de 1996 . Estabelece as diretrizes e bases da educação nacional. http://www.planalto.gov.br/ccivil_03/leis/19394.htm.

Brasil. (1997). Secretaria de Educação Especial - A educação dos Surdos - org. Giuseppe Rinaldi et al. MEC/SEESP.

Brasil. (2001). Lei $\mathrm{n}^{\mathrm{o}}$ 10.172, de 9 de janeiro de 2001. Aprova o Plano Nacional de Educação e dá outras providências. http://www.planalto.gov.br/ccivil_03/leis/leis_2001/110172.htm.

Brasil. (2002). Lei $\mathrm{n}^{\mathrm{o}} 10.436$ de 24 de abril de 2002. Dispõe sobre a Língua Brasileira de Sinais - Libras e dá outras providências. http://www.planalto.gov.br/ccivil_03/leis/2002/110436.htm.

Brasil. (2005), Decreto 5.626 de 22 de dezembro de 2005. Regulamenta a Lei $n^{\circ} 10.436$, de 24 de abril de 2002, que dispõe sobre a Língua Brasileira de Sinais - Libras, e o art. 18 da Lei no 10.098, de 19 de dezembro de 2000. http://www.planalto.gov.br/ccivil_03/_ato2004-2006/2005/decreto/d5626.htm.

Caridade, N. V. D. (2020). Processo escolar no ensino fundamental de uma aluna com surdez em escola de Macapá, Amapá. Research, Society and Development, 9(3), e185932722. https://doi.org/10.33448/rsd-v9i3.2722. 
Research, Society and Development, v. 10, n. 12, e587101221102, 2021

(CC BY 4.0) | ISSN 2525-3409 | DOI: http://dx.doi.org/10.33448/rsd-v10i12.21102

Fernandes Júnior, A. de J. dos S., \& Santos, M. E. M. (2021). Guia de Metodologia da Pesquisa para Jovens Cientistas. Even3 Publicações, 93 p.

Ferreira, G. da C. (2016). As dificuldades do ensino de física para surdos: proposta de ensino de ondas sonoras numa abordagem contextualizada. Monografia de conclusão de curso. Universidade Federal do Rio de Janeiro.

Gil, C. A. (2017). Como Elaborar Projetos de Pesquisa. (6a ed.), Atlas.

Mantoan, M. T. E. (2021). Inclusão Escolar: O que é? Por quê? Como fazer? Summus.

Mazucato, T. (2018). A elaboração do pré-projeto. In T. Mazucato (Org.), Metodologia da Pesquisa e do Trabalho Científico (pp. 40-46). Ed. Funepe.

Nader, J. M. V., Pires, M. L., Vietro, T. B. de, Silva, I. R., \& Bittencourt, Z. Z. L. C. (2007). Políticas públicas e iniciativas educacionais na educação do aluno surdo. http://alb.com.br/arquivo-morto/edicoes_anteriores/anais16/sem09pdf/sm09ss01_05.pdf.

Pereira, O. R. (2013). Alunos Surdos, Intérpretes de Libras e Professores: Atores em Contato na Universidade. Cadernos de Educação, 12(24), jan. jun. (pp. 73-96). https://doi.org/10.15603/1679-8104/ce.v12n24p73-96.

Quadros, R. M. de. (2008). Educação de surdos: a aquisição da linguagem: Artmed Editora, reimpressão.

Rodrigues, R., \& Gonçalves, J. C. (2020). Procedimentos de metodologia científica. (9a ed.): PAPERVEST. 195p.

Sabanai, N. L. (2007). A evolução da comunicação entre e com surdos no Brasil. http://www.helb.org.br/index.php/revista-helb/ano-1-no-1-12007/92-aevolucao-da-comunicacao-entre-e-com-surdos-no-brasil.

Sacks, O. (2010). Vendo Vozes: uma viagem ao mundo dos surdos. Tradução de Laura Teixeira Motta. Companhia das Letras. 